\title{
A Review of Robotic Interventional Neuroradiology
}

\author{
(1) C.B. Beaman, № N. Kaneko, (1) P.M. Meyers, and $\mathbb{1}^{\text {S }}$. Tateshima
}

\begin{abstract}
SUMMARY: Robotic interventional neuroradiology is an emerging field with the potential to enhance patient safety, reduce occupational hazards, and expand systems of care. Endovascular robots allow the operator to precisely control guidewires and catheters from a lead-shielded cockpit located several feet (or potentially hundreds of miles) from the patient. This has opened up the possibility of expanding telestroke networks to patients without access to life-saving procedures such as stroke thrombectomy and cerebral aneurysm occlusion by highly-experienced physicians. The prototype machines, first developed in the early 2000s, have evolved into machines capable of a broad range of techniques, while incorporating newly automated maneuvers and safety algorithms. In recent years, preliminary clinical research has been published demonstrating the safety and feasibility of the technology in cerebral angiography and intracranial intervention. The next step is to conduct larger, multisite, prospective studies to assess generalizability and, ultimately, improve patient outcomes in neurovascular disease.
\end{abstract}

ABBREVIATION: COVID-19 = coronavirus disease 2019

I: 1927, Moniz ${ }^{1}$ first used radiopaque dye and x-rays to visualize cerebral vessels in vivo. In the past 100 years, major advances have been made in the field of endovascular neurointervention, including treatment of aneurysms, arteriovenous malformations, subdural hematomas, and ischemic strokes. Despite this progress, these procedures still require an operator who stands next to the patient and manually injects contrast, manipulates wires and catheters, and operates $\mathrm{x}$-ray imaging, all while being exposed to ionizing radiation. In the 1980s, robotic systems were first introduced in a variety of disciplines to enhance precision and reproducibility in minimally-invasive surgical procedures. ${ }^{2-4}$ Early endovascular innovators adapted this technology and developed new remote-controlled catheter systems with the hopes of improving navigation and procedural precision. ${ }^{5,6}$ In recent years, interventional cardiologists have made tremendous progress with robotic technology. Large multicenter trials have demonstrated the safety and efficacy of robotics both in simple and in complex percutaneous coronary interventions. ${ }^{7,8}$ These successes paved

Received September 29, 2020; accepted after revision October 26.

From the Departments of Neurology (C.B.B.) and Radiology and Neurological

Surgery (P.M.M.), Columbia University Irving Medical Center, New York, New York; and Department of Radiological Sciences (N.K., S.T.), David Geffen School of Medicine, University of California Los Angeles, Los Angeles, California.

Please address correspondence to Charles B. Beaman, MD, PhD, Columbia

University Irving Medical Center, 710 W 168th St, New York, NY 10032; e-mail: cb3333@cumc.columbia.edu; @charlesbeaman

- Indicates open access to non-subscribers at www.ajnr.org

http://dx.doi.org/10.3174/ajnr.A6976 the way for investigations into the feasibility of robotic systems for endovascular neurointervention, including the implementation of automated maneuvers, machine learning, and remote operation.

As the indications for neuroendovascular intervention grow, operators spend more and more time in the angiography suite. Robotic systems have the potential to alleviate the occupational hazards associated with ionizing radiation. ${ }^{9}$ A concerning observational study was published in 2012, noting a predominance of left-sided brain tumors in interventional cardiologists. ${ }^{10,11} \mathrm{~A}$ much larger nationwide prospective cohort of 90,957 radiology technologists found a 2 -fold increase in the risk of brain cancer mortality and increased incidences of breast cancer and melanoma compared with controls. ${ }^{12}$ Even a single procedure has been shown to create radiation-induced DNA damage in circulating lymphocytes in operators. ${ }^{13}$ The concern is exacerbated by the growth of radial access, which exposes operators to higher doses of ionizing radiation compared with femoral access. ${ }^{14}$ As well as cancer-related risks, radiation increases the rates of cataracts and atherosclerosis during a long career. ${ }^{15,16}$ Interventionalists also have higher rates of orthopedic injuries, attributed to long hours standing in lead aprons. ${ }^{17}$ In addition, decreased occupational hazards may help improve distinct sex inequality in the field of neurointervention. Fewer than $10 \%$ of interventional radiologists are women, and this disparity may be partly attributed to fears related to radiation and orthopedic stress during pregnancy. ${ }^{18,19}$ Preliminary studies demonstrate that robotic 

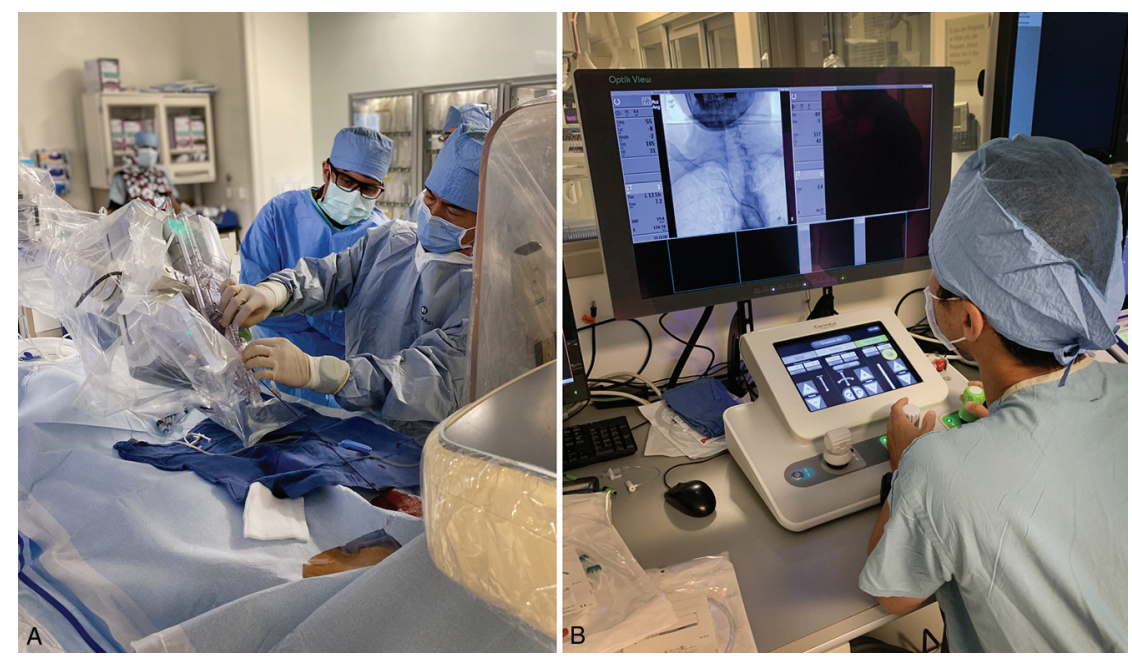

FIG 1. A, Sterile Corpath GRX patient-side robotic system during setup. $B$, Lead-shielded remote Corpath GRX control station during cerebral angiography procedure.
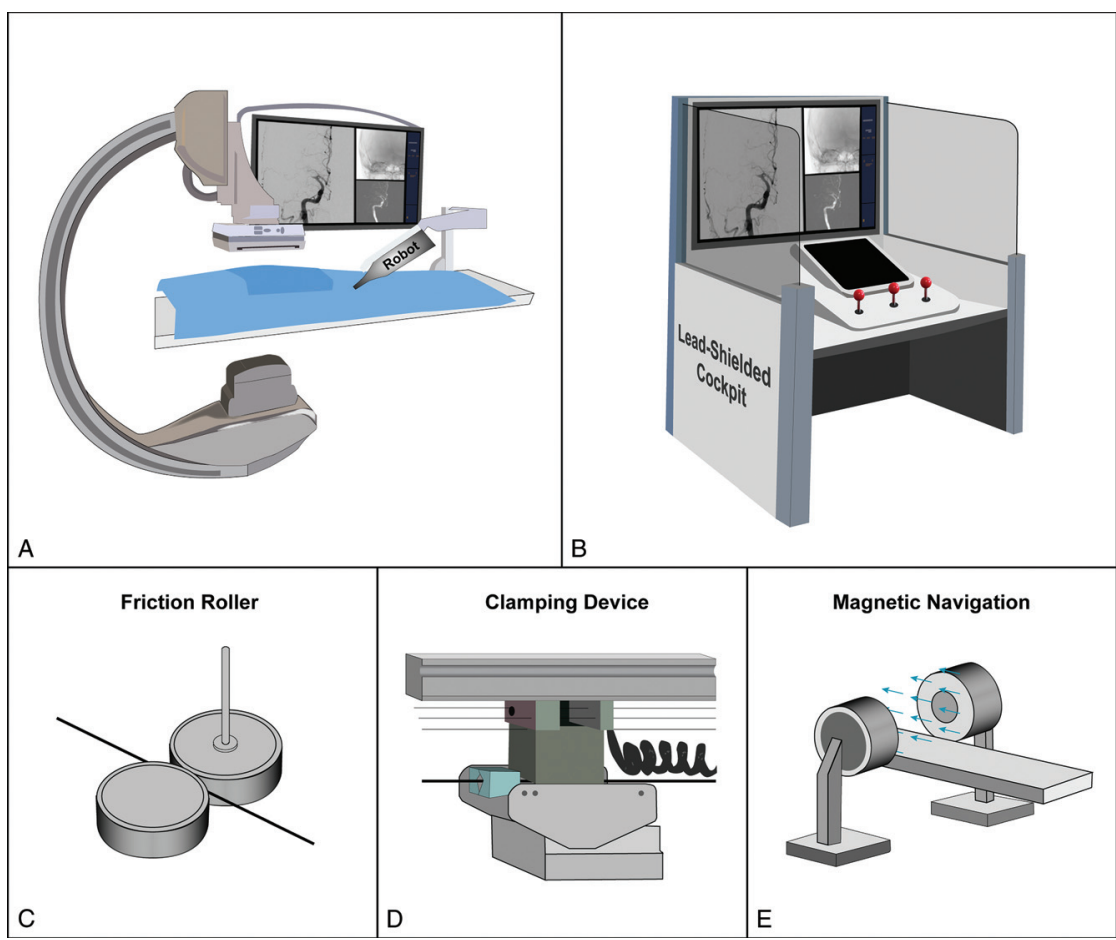

FIG 2. Robotic systems. $A$, Patient-side robot with articulating arm. $B$, Lead-shielded cockpit with monitors and controls. $C$, Friction roller drive mechanism. D, Clamping device mechanism. E, Magnetic navigation system.

endovascular systems can greatly mitigate these occupational risks. In the prospective Percutaneous Robotically Enhanced Coronary Intervention (PRECISE) study, the median radiation exposure to operators was reduced by $95.2 \%$ ( 0.98 versus $20.6 \mu \mathrm{Gy}, P<.001),{ }^{7}$ and a recent study demonstrated that robotic systems also significantly de-creased radiation doses to the patient (884 versus $1110 \mathrm{mGy}, P=.002) .{ }^{20}$ Furthermore, robotic systems may reduce the occupational spread of infection, such as coronavirus disease 2019
(COVID-19), by limiting staff exposure to the patient during procedures. ${ }^{21}$ Clearly, the opportunity for improved procedural safety is promising; however, it is of paramount importance to fully understand the technical strengths and limitations of current robotic systems to fully realize these ideals.

\section{Overiew of Robotics Specifications}

Current endovascular robotic systems consist chiefly of 2 components: the patient-side mechanical robot and the operator control station (Fig 1). The control station, originally designed to remain in the procedure room, is a radiation-shielded cockpit outfitted with computer monitors, various sensors, and joysticks to control the guidewire and catheters with millimeter-scale resolution. The robot is typically connected to an articulating arm next to the patient (Fig $2 A,-B$ ). It receives instructions (either through cables or wireless telecommunication) from the control station and physically manipulates the wires and catheters using linear and rotational drive motors. There are 3 principal drive mechanisms in use for axial motion of the guidewire and catheters. The first mechanism implements a friction or pinch roller to press the wire against a capstan and drive it forward and backward (Fig 2C). ${ }^{22,23}$ The second mechanism consists of a clamping device that grasps the wire and uses a linear motor to drive it axially along a shaft (Fig 2D). ${ }^{24-26}$ The third mechanism uses large externally generated magnetic fields for traction on a passive ferromagnetic catheter ( Fig 2E). ${ }^{27,28}$ The pinch roller and clamping mechanisms are more well-studied, but the magnetic system does have the benefit of distal tip navigation, which can theoretically allow omnidirectional distal tip control and in vivo wire reshaping. ${ }^{29}$

The first robotic system in general use, the CorPath 200 (launched in 2012 by Corindus, a Siemens Healthineers Company), implements pinch roller propulsion. It is an openarchitecture machine, compatible with 0.014-inch guidewires, rapid exchange catheters, and stent-delivery systems. With any new technology, it is critical to analyze potential failure modes and their causes and effects. Indeed, failure modes during robotic percutaneous coronary intervention were investigated by Harrison et 


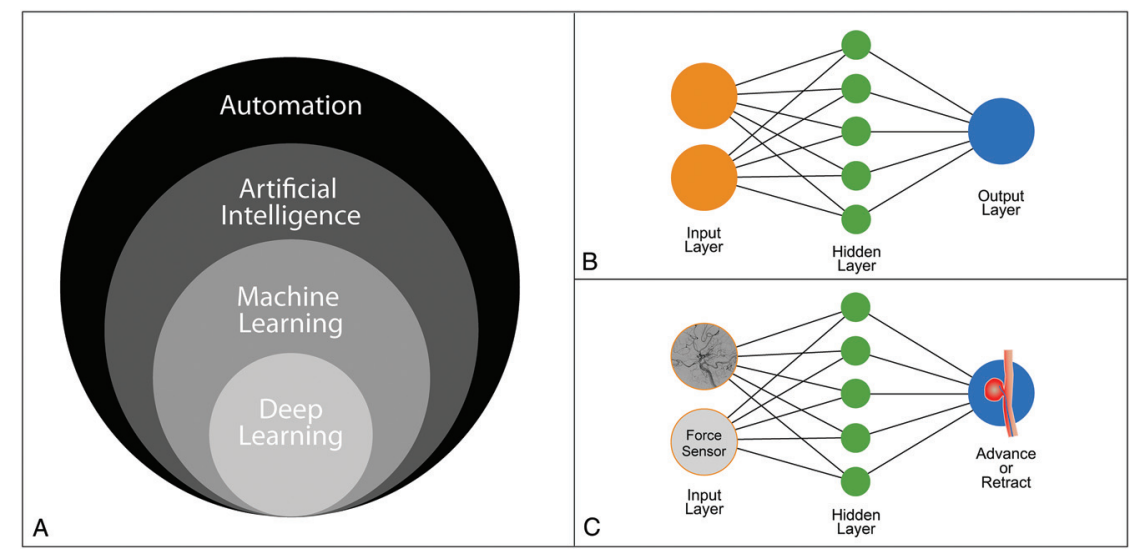

FIG 3. Automation in robotic neurointervention. $A$, Subfields of automation in computer science. $B$, Illustrated neural network with input layer, hidden layer, and output layer. $C$, Sample neural network with cerebral angiography and force sensor as inputs and the decision to advance or retract the catheter as the output.

$\mathrm{al},{ }^{30}$ who found that conversion to manual operation was required in 20 of 108 patients (18.5\%). Of these 20 cases, 12 required only partial manual assistance, defined as planned or unplanned temporary disengagement of the robotic drive for manual operation and then a return to full robotic operation. The other 8 cases required full conversion to manual operation for the duration of the procedure. The most common failure mode was related to lack of wire and catheter support and manipulation, which occurred in 9 cases. The remaining causes of failure were mostly due to known limitations of the system such as the need to use incompatible intracoronary imaging devices. Only 3 cases required manual intervention for adverse events such as vessel closure or dissection.

The second-generation CorPath GRX was cleared by the FDA for percutaneous coronary interventions in 2016 and for peripheral vascular interventions in 2018. It includes the ability to robotically control the guide catheter to enhance support, an essential feature for tortuous neurovasculature. The current working length is $20 \mathrm{~cm}$, or more precisely, $\pm 10 \mathrm{~cm}$ from a neutral starting position that can be manually changed. Britz et $\mathrm{al}^{22}$ conducted a neurovascular in vitro and porcine feasibility study and found that microcatheters occasionally herniated from the guide track. The herniation is similar to a line of train cars pushed from the back by a locomotive rather than pulled from the front by the same locomotive. Frictional forces prevent linear translation of force due to lateral instability of the line, or microcatheter in this case. In addition, they found that smaller-diameter devices, such as coils and stents, were too short to use in the guidewire track. This led the company to improve the machine by adding a Y-connector cover and adapter to prevent device herniation and a new driving gear to facilitate smaller-diameter devices. Corindus is now conducting a prospective, multicenter, clinical study to determine the effectiveness and safety of the robotic system in embolization of cerebral aneurysms compared with historical controls. ${ }^{31}$

\section{Automated Maneuvers and Machine Learning}

A principal advantage of endovascular robotics is the ability to automate maneuvers to reduce procedural time and decrease variability of repeat manual maneuvers. Currently available algorithms are sparse, but machine learning has the potential to augment the neurointerventionalist's tool kit. Rotate-onRetract was the first FDA-approved automated feature of the CorPath GRX Robotic System. With the feature activated, the robot will automatically rotate the guidewire during retraction to facilitate vessel selection. Preclinical work presented at the Transcatheter Cardiovascular Therapeutics Conference in 2017 demonstrated a significant reduction in mean wiring time $(20[\mathrm{SD}, 8]$ versus 48 [SD, 8] seconds) when the feature was enabled. ${ }^{32}$ In addition, Al Nooryani and Aboushokka ${ }^{33}$ published a case report describing its successful use in robot-assisted percutaneous coronary intervention to the left anterior descending coronary artery.

There is, however, a paucity of data regarding automated maneuvers in neuroendovascular cases. The cerebral vasculature has relatively small-diameter vessels that are structurally delicate with complex 3D branching arborization. ${ }^{34}$ In their in vitro and porcine feasibility study, Britz et $\mathrm{al}^{22}$ found inadvertent forward movement of the wire when delivering the microcatheter, risking perforation. This work led to the development of "Active Device Fixation," an open-loop control algorithm to counteract unexpected movements of the guidewire made in response to microcatheter actuation. ${ }^{35}$ This feature allows the operator to maintain the guidewire in a consistent position relative to the patient's anatomy and was recently implemented for the stent-coiling case report published by Mendes Pereira et al. ${ }^{36}$ Other automated features are currently in the development stage, including "Spin," a lesion-crossing algorithm that rotates the guidewire in an oscillating motion during advancement; "Wiggle," a navigation algorithm that automatically rotates the guidewire in a reciprocating motion during advancement; "Dotter," a lesion-crossing algorithm that advances and retracts in a stepwise fashion during advancement; and "Constant Speed," a measurement algorithm that allows the operator to select a constant drive speed. In the future, artificial intelligence and its subsets, machine learning and deep learning, may be fully integrated into robotic systems (Fig $3 A$ ). This integration entails collecting large datasets of procedural techniques, using statistical methods, and implementing multilayer neural networks to allow robotic systems to "learn" and ultimately improve their performance (Fig $3 B,-C$ ). The hope is that automating certain interventional techniques may reduce procedural variability and treatment time, leading to improved patient safety and outcomes.

One major limitation of current robotic endovascular systems is the loss of tactile feedback during manual procedures. Tactile feedback is additional sensory input that increases the operating physician's situational awareness beyond that provided by $2 \mathrm{D}$ or 3D visual imaging. Interventionalists can use this critical 


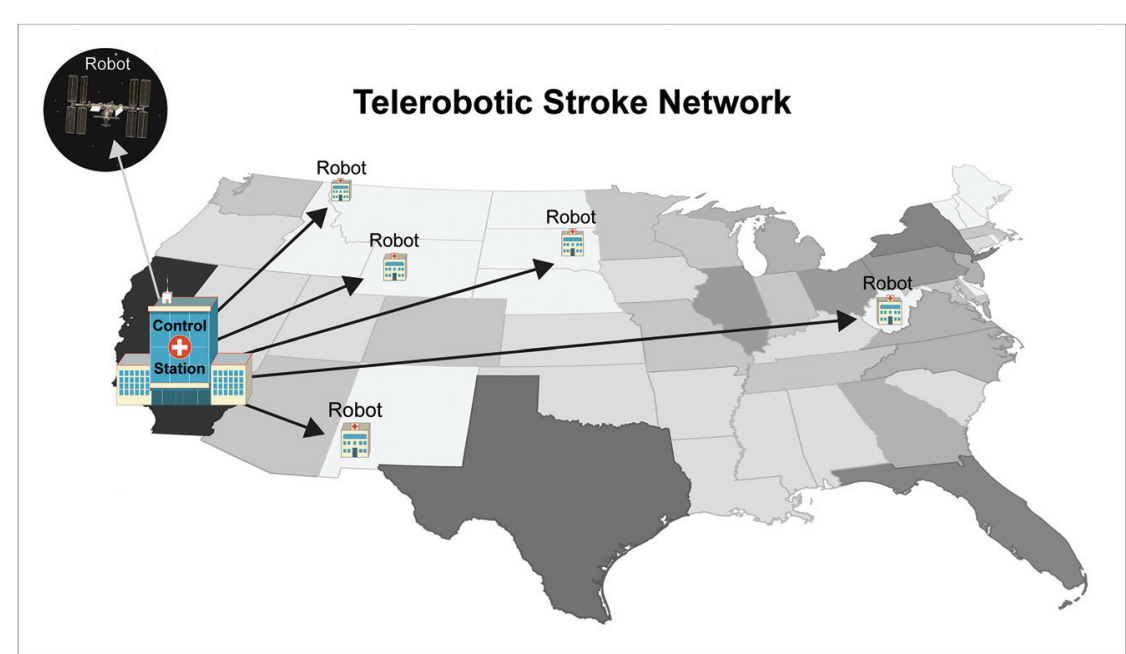

FIG 4. Telerobotic stroke network. A neurointerventionalist at the control station can operate multiple interventional robots to expand networks of care. "Robot" indicates potential sites of patient-side, interventional robots. Gray-scale indicates relative population size of each state. telestroke model to dramatically expand coverage for acute vascular procedures and further decrease time to treatment (Fig 4). Telementoring is another potential variant involving a remote physician who provides real-time observation and evaluation of the local physician's performance and may even be able to take control of the local tools to assist in the procedure. This may help provide lowvolume operators with high-volume skills, allowing safer acute neurointerventional procedures. ${ }^{44}$ Telementoring can also offer a solution to the issue of proctor availability under travel restrictions during a pandemic such as COVID-19. ${ }^{45}$

Early clinical examples of telesurgery date back to the 1990s, but remote cerebral angiography was not attempted until 2011 when $\mathrm{Lu}$ et $\mathrm{al}^{46}$ completed the procedure in an animal model in information to anticipate the release of potential energy in catheter systems to prevent wire advancement, vessel dissection, or perforation. Force-sensing capabilities were built into 1 early robotic catheter system by Negoro et al. ${ }^{5}$ The diameter of their force sensor was $1.2 \mathrm{~mm}$ (0.047 inches), with a resolution of $<0.5 \mathrm{mN}$, and a frequency response up to $2 \mathrm{kHz}$. Guo et $\mathrm{al}^{37}$ also developed a force-sensing catheter with a fiber pressure sensor (OPP-M40; OpSens). Their probe diameter was $0.25 \mathrm{~mm}(0.010$ inches), a size more compatible with neuroendovascular procedures. They also developed an early safety warning system with a pressure threshold function that can be changed in real-time to adapt to different patients and their vascular characteristics. Future research may also allow interventionalists to physically sense the pressure in the guidewire or catheter, a technology known as haptics. For example, haptic technology is incorporated into many commercially available game controllers. The additions of force-sensing and haptic technology to robotic endovascular systems will likely be key areas of future research.

\section{Telerobotics}

Inequality in the geographic distribution of subspecialty health care limits medical access to a significant proportion of people. Only one-fifth of the US population has direct access to a thrombectomy-capable center within 15 minutes of travel time, and relying on interhospital transfer has unfortunately been associated with a treatment delay of up to 95 minutes. ${ }^{38,39}$ Recent research has shown that even a 15-minute delay in treatment is associated with a $10 \%$ decrease in the likelihood of good functional outcome. ${ }^{40,41}$ In the past 2 decades, telestroke has become one of the most effective telemedicine applications by showing increased rates of tPA administration, reduced door-to-needle times, and decreased patient death and dependency. ${ }^{42,43}$

Telerobotics refers to transmission of data through telecommunication systems to allow the active control of instruments by a remote physician located at a distance from the interventional suite. The principal goal of telerobotics is to build on the
Beijing, China, from a control center in Kagawa, Japan. In 2017, Madder et $\mathrm{al}^{47}$ first conducted telestenting of coronary arteries in 20 patients from approximately 55 feet away over Wi-Fi. Technical success (without conversion to manual operation) was achieved in $86.4 \%$ of lesions, and procedural success $(<30 \%$ residual stenosis) was achieved in $95 \%$ of patients. The first-inhuman, long-distance, telerobotic coronary stent was recently placed by Patel et $\mathrm{al}^{48}$ in India in 2019. They successfully telestented 5 patients with single, type A coronary artery lesions from a distance of 20 miles. The mean time delay between the remote console and the in-lab robotic system was only $53 \mathrm{~ms}$, well below perceptible limits. Further clinical research steps will be to conduct multicenter evaluations of teleoperation of both simple and complex lesions without in-lab operators as backup. Neurointerventional procedures have yet to be completed from a remote distance, but this will likely be attempted in the coming years.

Preliminary investigations into network performance and its impact on telerobotics are also underway. Several groups have demonstrated that network latencies of $\leq 250 \mathrm{~ms}$ are not noticeable to the operator and do not impact performance. ${ }^{49-51}$ However, the impact of other network features such as jitter, redundancy, and bandwidth have yet to be fully explored. ${ }^{51}$ In a world rife with data security breaches, end-to-end encryption to ensure patient confidentiality and safety will be necessary. Commodity internet is widely available, and its use would greatly increase telerobotic adaptation, but special-purpose restricted networks may be more reliable. Further technical investigation of network performance is essential to the widespread expansion of telerobotics.

\section{Clinical Applications of Robotic Neurointervention}

The early clinical work in robotic endovascular intervention was primarily completed in cardiac and peripheral vascular studies. In 2007, Dabus et $\mathrm{al}^{27}$ began to conduct neuroendovascular procedures and published a series of 10 cases using magnetic 
navigation. Yet, during the next decade, little clinical progress was made in neurovascular robotics. In 2016, Lu et al ${ }^{23}$ published 15 cases of robot-assisted cerebral angiography using the vascular interventional robot (VIR-2; Navy General Hospital of People's Liberation Army, Beijing University) without complications. In 2017, Vuong et $\mathrm{al}^{52}$ used the Magellan Robotic Catheter System (Hansen Medical) and shared their experience with 9 robotassisted cerebral angiograms and 18 robot-assisted intracranial interventions. The details of the interventional cases were not published; yet they compared robot-assisted angiography with matched angiographic controls and found no significant differences in procedural time, fluoroscopy times, and contrast volumes. In 2020, Sajja et $\mathrm{al}^{53}$ published their experience using the CorPath GRX Robotic System to complete 7 transradial cerebral angiograms and 3 cases of carotid artery angioplasty and stent placement. 3 of the 7 angiography cases were converted to manual operation after discovery of a bovine arch that necessitated catheter exchange.

A similar research group conducted a retrospective comparison of transradial robot-assisted carotid stent placement with manual stent placement and found that the mean procedural duration was significantly longer while using the robot (85.0 [SD, 14.3] versus 61.2 [SD, 17.5] minutes), but there was no significant difference in other procedural characteristics such as fluoroscopy time, contrast dose, radiation exposure, catheter exchanges, technical success, transfemoral conversion, and complications. ${ }^{54}$ Nogueira et $\mathrm{al}^{55}$ also recently treated 4 patients with severe symptomatic carotid stenosis and achieved technical and procedural success. All steps of the procedure were completed by the robotic system except for navigation and deployment of the stent, which is currently incompatible. The first true intracranial robotic neurointervention was recently conducted by Mendes Pereira et al ${ }^{36}$ in Toronto, Ontario, Canada. They conducted a stent-assisted coiling procedure to treat a $12-\mathrm{mm}$ basilar trunk aneurysm. Other than the placement of the guide-sheath and coaxial catheter that was performed manually, all manipulations of the microcatheter, microguidewire, intracranial stent, and aneurysm coils were performed under robotic control.

\section{Limitations}

The field of robotic interventional neuroradiology is still in its infancy. Prototype systems were initially developed to conduct robotic percutaneous coronary intervention; thus, current machines are not perfectly adapted to neurovascular procedures. The CorPath GRX, for example, is not capable of implementing the triaxial approach (guiding catheter, distal access catheter, and microcatheter) necessary for many neurovascular cases; it cannot manipulate over-the-wire equipment, precluding most modern devices; and it cannot robotically deploy some devices without manual assistance. Any catheter with a side port, such as balloon guide, cannot fit into the disposable cassette of the CorPath GRX. In addition, the current working length is $20 \mathrm{~cm}$, but $40 \mathrm{~cm}$ would be more appropriate for neurovascular cases. Moreover, the range of motion of the CorPath GRX robotic arm is limited and should be more versatile in future systems.

One of the major goals of robotic endovascular systems is to increase efficiency and decrease procedural time; yet, early research indicates prolonged procedural time when using the robot. ${ }^{54}$ It is unclear whether this issue is entirely due to inherent deficiencies of current robots or more related to limited operator experience. Clearly, a standardized training curriculum is needed to optimize physician interaction with robotic systems. Future devices should also measure and optimize physician performance and help trainees learn new procedures in an immersive simulated environment. ${ }^{56} \mathrm{~A}$ third-generation robotic system is currently under development and will undoubtedly address some of these deficiencies. Yet, given the open-architecture nature of current technology, ongoing development of new microwires, catheters, and advanced intravascular imaging tools will necessitate frequent updates of robotic systems to facilitate them. In the future, angiography, robotics, and device companies should work synergistically to create a streamlined workflow to guarantee compatibility and decrease procedural time.

Acute stroke care fundamentally changed following the publication of landmark endovascular thrombectomy trials in 2015. Despite this paradigm shift, limited access to care remains a tremendous impediment to improving patient outcomes. The pinnacle of robotic neurointervention may be completing an acute thrombectomy in a remote geographic location. To achieve this goal, several critical roles need to be defined. A physician must be on-site to obtain manual vascular access, place the sheath, and guide the catheter into the arch; support staff must be present in the room to operate the table; and personnel must be trained to efficiently set up the robotic system to decrease lead time in emergency cases. Published literature has not demonstrated an increase in case complications with robot-assisted interventions; yet, no one has actually shown the ability of the robot to assist in the resolution of endovascular complications. During a fully remote procedure, there may be no on-site physician capable of converting to manual operation to avert a serious adverse event. Other large-scale logistical concerns remain, such as the following: which hospitals would most benefit from the installation of robotic systems for neurointervention, how much training is needed for physicians and staff to safely perform robotic procedures, would medical licensing boards allow interstate teleoperation, and who is held liable if the robot or telecommunications system makes an error?

\section{CONCLUSIONS}

Sociopolitical issues often provide a catalyst for the dissemination of new technology. Indeed, social distancing required during the COVID-19 pandemic has ushered in the rise of telemedicine. The field of endovascular robotics can leverage this growth to eliminate legal and geographic barriers to expand stroke networks worldwide. Future autonomous robotic systems may also provide care in combat zones, spacecraft, and other areas where access to health care is greatly restricted. ${ }^{57}$ Other impending upgrades include improved sensors, tactile feedback, machine learning algorithms, and autonomous functions to enhance precision and reduce (or remove) human error. The initial goal of robotic neurointervention is to replicate the safety and success of traditional, manual approaches. However, in the coming years, basic and clinical research will determine whether robotic systems can truly 
improve technologic capabilities, offer remote teleoperation, and improve patient outcomes.

Disclosures: Satoshi Tateshima-UNRELATED: Consultancy: Corindus Vascular Robotics, Medtronic, Stryker, Cerenovus, Balt USA; Grants/Grants Pending: MicroVention, Biomedical Solutions Inc; Payment for Lectures Including Service on Speakers Bureaus: Kaneka Medix, Century Medical Inc, Terumo; Stock/Stock Options: Corindus Vascular Robotics.

\section{REFERENCES}

1. Moniz E. Arterial encephalography, its importance in the location of cerebral tumors. https://thejns.org/view/journals/ j-neurosurg/21/2/article-p145.xml. Accessed August 1, 2020

2. Kwoh YS, Hou J, Jonckheere EA, et al. A robot with improved absolute positioning accuracy for CT guided stereotactic brain surgery. IEEE Trans Biomed Eng 1988;35:153-60 CrossRef Medline

3. Davies BL, Hibberd RD, Ng WS, et al. The development of a surgeon robot for prostatectomies. Proc Inst Mech Eng H 1991;205:35-38 CrossRef Medline

4. Sung GT, Gill IS. Robotic laparoscopic surgery: a comparison of the DA Vinci and Zeus systems. Urology 2001;58:893-98 CrossRef Medline

5. Negoro M, Tanimoto M, Arai F, et al. An intelligent catheter system robotic controlled catheter system. Interv Neuroradiol 2001;7:11113 CrossRef Medline

6. Beyar R, Wenderow T, Lindner D, et al. Concept, design and preclinical studies for remote control percutaneous coronary interventions. EuroIntervention 2005;1:340-45 Medline

7. Weisz G, Metzger DC, Caputo RP, et al. Safety and feasibility of robotic percutaneous coronary intervention: PRECISE (Percutaneous Robotically-Enhanced Coronary Intervention) study. J Am Coll Cardiol 2013;61:1596-1600 CrossRef Medline

8. Mahmud E, Naghi J, Ang L, et al. Demonstration of the safety and feasibility of robotically assisted percutaneous coronary intervention in complex coronary lesions: results of the CORA-PCI Study (Complex Robotically Assisted Percutaneous Coronary Intervention). JACC Cardiovasc Interv 2017;10:1320-27 CrossRef Medline

9. Kim KP, Miller DL, Balter S, et al. Occupational radiation doses to operators performing cardiac catheterization procedures. Health Phys 2008;94:211-27 CrossRef Medline

10. Roguin A, Goldstein J, Bar O. Brain tumours among interventional cardiologists: a cause for alarm: report of four new cases from two cities and a review of the literature. EuroIntervention 2012;7:108186 [Database] CrossRef Medline

11. Roguin A, Goldstein J, Bar O, et al. Brain and neck tumors among physicians performing interventional procedures. Am J Cardiol 2013;111:1368-72 CrossRef Medline

12. Rajaraman P, Doody MM, Yu CL, et al. Cancer Risks in U.S.: radiologic technologists working with fluoroscopically guided interventional procedures, 1994-2008. AJR Am J Roentgenol 2016;206:110108; quiz 1109 CrossRef Medline

13. El-Sayed T, Patel AS, Cho JS, et al. Radiation-induced DNA damage in operators performing endovascular aortic repair. Circulation 2017;136:2406-16 CrossRef Medline

14. Plourde G, Pancholy SB, Nolan J, et al. Radiation exposure in relation to the arterial access site used for diagnostic coronary angiography and percutaneous coronary intervention: a systematic review and meta-analysis. Lancet 2015;386:2192-2203 CrossRef Medline

15. Smilowitz NR, Balter S, Weisz G. Occupational hazards of interventional cardiology. Cardiovasc Revasc Med 2013;14:223-28 CrossRef Medline

16. Andreassi MG, Piccaluga E, Gargani L, et al. Subclinical carotid atherosclerosis and early vascular aging from long-term low-dose ionizing radiation exposure: a genetic, telomere, and vascular ultrasound study in cardiac catheterization laboratory staff. JACC Cardiovasc Interv 2015;8:616-67 CrossRef Medline

17. Goldstein JA, Balter S, Cowley M, et al; Interventional Committee of the Society of Cardiovascular Interventions. Occupational hazards of interventional cardiologists: prevalence of orthopedic health problems in contemporary practice. Catheter Cardiovasc Interv 2004;63:407-11 CrossRef Medline

18. Parra-Farinas C. How to fight the fear under the $\mathbf{x}$-ray beam: interventional neuroradiology fellow mom to be. Stroke 2020;51:e12123 CrossRef Medline

19. Vu CT, Elder DH. Pregnancy and the working interventional radiologist. Semin Intervent Radiology 2013;30:403-07 CrossRef Medline

20. Patel TM, Shah SC, Soni YY, et al. Comparison of robotic percutaneous coronary intervention with traditional percutaneous coronary intervention: a propensity score-matched analysis of a large cohort. Circ Cardiovasc Interv 2020;13:e008888 CrossRef Medline

21. Tabaza L, Virk HU, Janzer S, et al. Robotic-assisted percutaneous coronary intervention in a COVID-19 patient. Catheter Cardiovasc Interv 2020 May 20. [Epub ahead of print] CrossRef Medline

22. Britz GW, Tomas J, Lumsden A. Feasibility of robotic-assisted neurovascular interventions: initial experience in flow model and porcine model. Neurosurgery 2020;86:309-14 CrossRef Medline

23. Lu WS, Xu WY, Pan F, et al. Clinical application of a vascular interventional robot in cerebral angiography. Int J Med Robot 2016;12:132-36 CrossRef Medline

24. Guo J, Guo S, Xiao N, et al. A novel robotic catheter system with force and visual feedback for vascular interventional surgery. International Journal of Mechatronics and Automation 2012;2:15-24 CrossRef

25. Wang K, Chen B, Lu Q, et al. Design and performance evaluation of real-time endovascular interventional surgical robotic system with high accuracy. Int J Med Robot 2018;14:e1915 CrossRef Medline

26. Arai F, Fujimura R, Fukuda T, et al. New catheter driving method using linear stepping mechanism for intravascular neurosurgery. In: Proceedings 2002 IEEE International Conference on Robotics and Automation (Cat No 02CH37292), Washington, DC. May 11-15, 2002:2944-49

27. Dabus G, Gerstle RJ, Cross DT, et al. Neuroendovascular magnetic navigation: clinical experience in ten patients. Neuroradiology 2007;49:351-55 CrossRef Medline

28. Jin QI, Pehrson S, Jacobsen PK, et al. Efficacy and safety of atrial fibrillation ablation using remote magnetic navigation: experience from 1,006 procedures. J Cardiovasc Electrophysiol 2016;27:S23-28 CrossRef Medline

29. Krings T, Finney J, Niggemann P, et al. Magnetic versus manual guidewire manipulation in neuroradiology: in vitro results. Neuroradiology 2006;48:394-401 CrossRef Medline

30. Harrison J, Ang L, Naghi J, et al. Robotically-assisted percutaneous coronary intervention: reasons for partial manual assistance or manual conversion. Cardiovasc Revasc Med 2018;19:526-31 CrossRef Medline

31. CorPath ${ }^{\circledR}$ GRX Neuro Study. https://ClinicalTrials.gov/show/ NCT04236856. Accessed August 15, 2020

32. Ryan Madder, William Lombardi, Manish Parikh, et al. TCT-539 impact of a novel advanced robotic wiring algorithm on time to wire a coronary artery bifuraction in a porcine model. $\mathrm{J} \mathrm{Am}$ Coll Cardiol 2017;70:B223 CrossRef

33. Al Nooryani A, Aboushokka W. Rotate-on-retract procedural automation for robotic-assisted percutaneous coronary intervention: first clinical experience. Case Rep Cardiol 2018;2018:6086034 CrossRef Medline

34. Meyers PM, Schumacher HC, Tanji K, et al. Use of stents to treat intracranial cerebrovascular disease. Annu Rev Med 2007;58:107-22 CrossRef Medline

35. Britz GW, Panesar SS, Falb P, et al. Neuroendovascular-specific engineering modifications to the CorPath GRX Robotic System. J Neurosurg 2019 Nov 29. [Epub ahead of print] CrossRef Medline 
36. Mendes Pereira V, Cancelliere NM, Nicholson P, et al. First-inhuman, robotic-assisted neuroendovascular intervention. $J$ Neurointerv Surg 2020;12:338-40 CrossRef Medline

37. Guo J, Jin X, Guo S. Study of the operational safety of a vascular interventional surgical robotic system. Micromachines (Basel) 2018;9:119 CrossRef Medline

38. Saver JL, Goyal M, van der Lugt A, et al; HERMES Collaborators. Time to treatment with endovascular thrombectomy and outcomes from ischemic stroke: a meta-analysis. JAMA 2016;316:1279-88 CrossRef Medline

39. Sarraj A, Savitz S, Pujara D, et al. Endovascular thrombectomy for acute ischemic strokes: current US access paradigms and optimization methodology. Stroke 2020;51:1207-17 CrossRef Medline

40. He AH, Churilov L, Mitchell PJ, et al. Every 15-min delay in recanalization by intra-arterial therapy in acute ischemic stroke increases risk of poor outcome. Int J Stroke 2015;10:1062-67 CrossRef Medline

41. Snyder T, Agarwal S, Huang J, et al. Stroke treatment delay limits outcome after mechanical thrombectomy: stratification by arrival time and ASPECTS. I Neuroimaging 2020;30:625-30 CrossRef Medline

42. Muller-Barna P, Hubert GJ, Boy S, et al. TeleStroke units serving as a model of care in rural areas: 10-year experience of the TeleMedical Project for Integrative Stroke Care. Stroke 2014;45:2739-44 CrossRef Medline

43. Audebert HJ, Schultes K, Tietz V, et al; Telemedical Project for Integrative Stroke Care (TEMPiS). Long-term effects of specialized stroke care with telemedicine support in community hospitals on behalf of the Telemedical Project for Integrative Stroke Care (TEMPiS). Stroke 2009;40:902-08 CrossRef Medline

44. El Nawar R, Lapergue B, Piotin M, et al; ETIS Investigators. Higher annual operator volume is associated with better reperfusion rates in stroke patients treated by mechanical thrombectomy: the ETIS Registry. JACC Cardiovasc Interv 2019;12:385-91 CrossRef Medline

45. Bechstein M, Elsheikh S, Wodarg F, et al. Interhospital teleproctoring of endovascular intracranial aneurysm treatment using a dedicated live-streaming technology: first experiences during the COVID-19 pandemic. BMJ Case Rep 2020;13:e016722 CrossRef Medline

46. Lu WS, Wang DM, Liu D, et al. Regarding "Application of robotic telemanipulation system in vascular interventional surgery". J Vasc Surg 2013;57:1452-53 CrossRef Medline
47. Madder RD, VanOosterhout SM, Jacoby ME, et al. Percutaneous coronary intervention using a combination of robotics and telecommunications by an operator in a separate physical location from the patient: an early exploration into the feasibility of telestenting (the REMOTE-PCI study). EuroIntervention 2017;12:156976 CrossRef Medline

48. Patel TM, Shah SC, Pancholy SB. Long distance tele-robotic-assisted percutaneous coronary intervention: a report of first-in-human experience. EClinicalMedicine 2019;14:53-58 CrossRef Medline

49. Rayman R, Croome K, Galbraith N, et al. Long-distance robotic telesurgery: a feasibility study for care in remote environments. Int $J$ Med Robot 2006;2:216-24 CrossRef Medline

50. Xu S, Perez M, Yang K, et al. Determination of the latency effects on surgical performance and the acceptable latency levels in telesurgery using the $\mathrm{dV}$-Trainer ${ }^{\circledR}$ simulator. Surg Endosc 2014;28:2569-76 CrossRef Medline

51. Madder RD, VanOosterhout S, Mulder A, et al. Network latency and long-distance robotic telestenting: exploring the potential impact of network delays on telestenting performance. Catheter Cardiovasc Interv 2020;95:914-19 CrossRef Medline

52. Vuong SM, Carroll CP, Tackla RD, et al. Application of emerging technologies to improve access to ischemic stroke care. Neurosurg Focus 2017;42:E8 CrossRef Medline

53. Sajja KC, Sweid A, Al Saiegh F, et al. Endovascular robotic: feasibility and proof of principle for diagnostic cerebral angiography and carotid artery stenting. J Neurointerv Surg 2020;12:345-49 CrossRef Medline

54. Weinberg JH, Sweid A, Sajja K, et al. Comparison of robotic-assisted carotid stenting and manual carotid stenting through the transradial approach. J Neurosurg 2020 Aug 28. [Epub ahead of print] CrossRef Medline

55. Nogueira RG, Sachdeva R, Al-Bayati AR, et al. Robotic assisted carotid artery stenting for the treatment of symptomatic carotid disease: technical feasibility and preliminary results. J Neurointerv Surg 2020;12:341-44 CrossRef Medline

56. Kreiser K, Strober L, Gehling KG, et al. Simulation training in neuroangiography-validation and effectiveness. Clin Neuroradiol 2020 Apr 17. [Epub ahead of print] CrossRef Medline

57. Panesar SS, Ashkan K. Surgery in space. Br J Surg 2018;105:1234-43 CrossRef Medline 